\title{
Ianula (1970) revisited. Lessons from a pioneering study
}

\author{
Aldo Marchetto* \\ National Research Council, Water Research Institute, Largo Tonolli 50, 28922 Verbania Pallanza, Italy
}

\begin{abstract}
More than fifty years ago, G.E. Hutchinson published "Ianula: an account of the history and development of the Lago di Monterosi, Latium, Italy", a detailed report of one of the first multi-disciplinary palaeolimnological studies. The main result of that study was that the last Glacial climate in peninsular Italy was not only cold but also dry, in contrast with the assumption prevalent at that time of wet "pluvials" in Glacial stages of the northern Mediterranean. These finding were confirmed by more recent studies on other volcanic lakes in Italy. Furthermore, the authors found a major change in ecosystem structure and concluded that it was caused by the building of a road in Roman time. Comparing Monterosi pollen profile with those obtained from cores in other lakes in Central Italy and in the Adriatic Sea, I suggest an alternative hypothesis linking the dramatic environmental change recorded to soil development during forest onset at the beginning of the Holocene. The original report made available a large share of the data set, as a pioneering example of Open Data, allowing a re-examination of the results and the formulation of new hypotheses, underlying the importance of open data in environmental science.
\end{abstract}

\section{INTRODUCTION}

Environmental monitoring by regular observations allows us to identify changes occurring in ecosystems (Franklin, 1988). However, environmental changes may have occurred before observation started (e.g. Ruggiu et $a l ., 1998)$. In this case, it is possible to infer the past conditions of lake ecosystems using lake sediments, which can be considered natural archives documenting the evolution of the lake, including its chemical, physical and biological features, of its catchment and of the regional climate (Oldfield, 2005; Smol, 2009). To obtain a more detailed picture of past environment, considering that not all organisms leave persistent morphological or biochemical remains in lake sediments, it is useful to study as many features as possible.

One of the first multidisciplinary palaeolimnological studies was performed on Lake Monterosi, Central Italy, by a team of researchers led by G.E. Hutschinson. Volcanic lakes in Central Italy were considered for this pioneering study because they were not greatly influenced

Corresponding author: aldo.marchetto@enr.it

Key words: Palaeolimnology; volcanic lakes; Monterosi.

Received: 14 April 2021.

Accepted: 15 May 2021.

This work is licensed under a Creative Commons Attribution NonCommercial 4.0 License (CC BY-NC 4.0).

${ }^{\circ}$ Copyright: the Author(s), 2021

Licensee PAGEPress, Italy

J. Limnol., 2021; 80(3):2022

DOI: 10.4081/jlimnol.2021.2022 by the accumulation of till in post-glacial time. Lake Monterosi was chosen among them because it was small and shallow, and relatively easy to core with the material available at that time (Hutchinson, 1970).

The report is very impressive, including chapters on present ecological condition of the lakes, the history or the surrounding area, petrography of the lava in the catchment, chemistry and mineralogy of the sediment as well as profile along the cores of remains of pollen, diatoms, chrysophyte cysts, porifera, chironomids and "other flora and fauna", such as cladocera.

The very high quality of the study, as well as the completeness of the report, made this study an example of high quality multidisciplinary study, frequently reported as an example in limnology text books (e.g., Moss, 1998; Wetzel, 2001), and represented a source of inspiration and a model study for palaeolimnologists.

The main result of the Monterosi work was that the last Glacial climate in peninsular Italy was not only cold but also dry, in contrast with the assumption prevalent at that time of wet "pluvials" in Glacial stages of the northern Mediterranean (Bonatti, 1966). These finding were confirmed later by pollen profiles taken in other lakes in Central Italy (e.g. Lowe et al., 1996).

Collected data were extensively reported in tables and/or graphs, allowing us to re-examine the results on the light of the experience collectively accumulated in the following fifty years of palaeolimnological studies. The availability of the original data represents another pioneering aspect of the study, in line with what is now considered Open Data according to the FAIR principles (Wilkinson et al., 2016).

\section{The history of the lake and the original interpretation}

Summarizing the large amount of data contained in the original report (Hutchinson, 1970), we can describe 
the history of the lake as a sequence of three major periods. At the basis of the core, the first part of the lake history (phase A) was characterized by the presence of aquatic plants, periphytic diatoms, remains of cyanobacteria (Gleotrichia) and Chaoborus, indicating a moderate trophic status. A second longer phase (B) of oligotrophic condition was indicated by an increase in aquatic plant pollen and the presence of Sphagnum and of epipsammic diatoms, typical of the bottom of very transparent lakes. This phase finished abruptly at around $160-\mathrm{cm}$ depth, when the calcium content of the sediment increased and clear signs of lake eutrophy appeared: aquatic plant pollen declined, and the diatom flora was dominated by species typical of nutrient rich lakes (phase C). Cyanobacteria abundance also increased, together with the onset of a rich chironomid and cladocera fauna. After this phase, the trophic status of the lake was reduced, but not enough to make the ecosystem able to come back to its previous state. Based on radiocarbon data, the shift from phase $B$ to phase $C$ was dated at 2,220 \pm 120 years B.P. No natural events accounting for such a large ecosystem change could be found around this date. However, in 171 b.C. the via Cassia was built, running around the southern slope of the Monterosi catchment and affecting the lake outlet. For this reason, it was assumed that the changes in lake ecosystem were due to increased sedimentation due to the road building and to changes in the hydrology of the lake due to outlet alteration. The increased presence of large $(>40 \mu \mathrm{m})$ pollen grains of Graminaae and of Plantago pollen at ca. $60 \mathrm{~cm}$ depth was interpreted as a sign of re-settlement of agriculture in the Middle Ages, after a period of abandon related to the end of the Roman Empire (Bonatti, 1970).

\section{Critical points}

A critical point in this study is related to the very low sedimentation rate of Lake Monterosi. Two sediment cores were collected, ca. $2.5 \mathrm{~m}$ long, covering the whole Holocene and part of the Late Glacial, indicating a sedimentation rate of about $0.01 \mathrm{~cm} \mathrm{y}^{-1}$, so that the temporal resolution of the study was also low. The authors were aware of this fact, and at the end of the chapter on pollen, Bonatti (1970) wrote: "Cores from other volcanic basins in Central Italy where the sedimentation rate was possibly higher than in Monterosi may reveal details of a stratigraphic sequence which was only outlined in the present work".

A second, and more relevant, critical point is related to the source material used for radiocarbon dating. Accurate sediment dating is a relevant difficulty in palaeolimnological studies, and can be reliably attained in some cases only by combining multiple techniques. For example, Zolitscka and Negendank (1996) used together varve counting, tephra analysis and radiocarbon dating to obtain an accurate chronology of the sediment of the Lago Grande di Monticchio. In the case of Lake Monterosi, the authors relayed entirely on the (at that time) recently developed technique of radiocarbon dating, and core chronology was only based on eight ${ }^{14} \mathrm{C}$ analyses, performed on bulk sediment section, 4 to $35-\mathrm{cm}$ tick (Fig. 1).

Later literature (for a review, see Björck and Wohlfarth, 2001) showed that bulk sediment may contain carbon deriving from a variety of sources, such as rests of lake and terrestrial organisms, and mineral and organic components of catchment soils, which may contain carbon of different age. The typical source of error in ra-

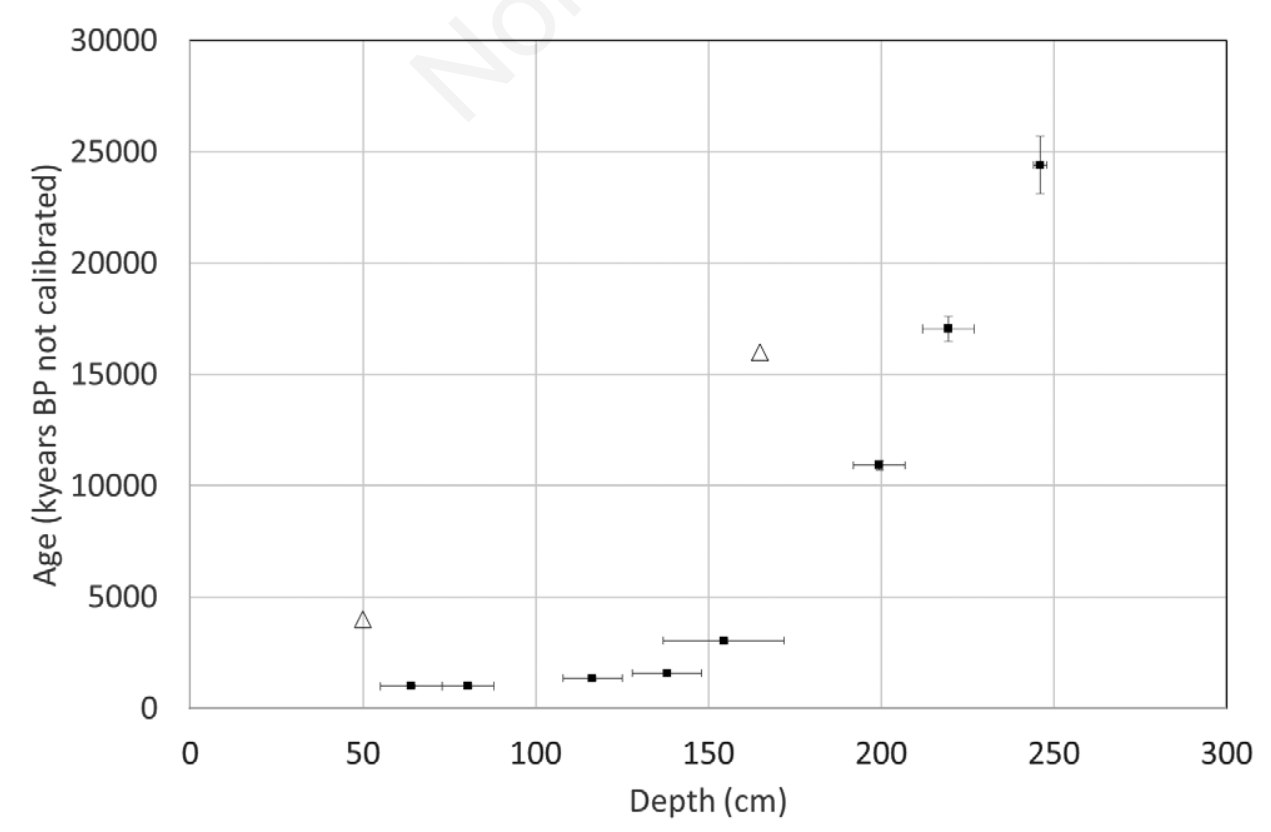

Fig. 1. Age-depth relationships with standard error for the ${ }^{14} \mathrm{C}$ dating of bulk sediment in Lake Monterosi core 1-A (redrawn from data in Bonatti, 1970). Horizontal bars denote sample thickness. Triangles indicate alternative approximate dates obtained by correlating the pollen profile with dated cores from lakes Albano and Nemi (Lowe et al., 1996). 
diocarbon dating of bulk lake sediment is the presence of persistent organic material, such as lignine or even coal, older than the sediment itself. In this case, radiocarbon dates would be older than the actual sediment deposition. For this reason, a present-day "more or less unspoken rule" in sediment dating (Björck and Wohlfarth, 2001) suggests to avoid bulk sediment for radiocarbon dating, and to prefer dating macroremains from terrestrial plants or from aquatic plants utilizing atmospheric $\mathrm{CO}_{2}$.

Contamination of bulk sediment by younger carbon is more rarely reported, However, the presence of rooted macrophytes can influence bulk sediment samples by contamination through rootlets or humic acids percolating down into the sediment (Björck and Wohlfarth, 2001).

In the case of the shallow Lake Monterosi, most of lake bottom is covered by rooted macrophytes, and the pollen diagram (Fig. 2b) reveals that this was the case also in the past. Macrophyte roots may then have caused "younger" organic carbon to reach deeper sediment.

For these reasons, we can question the accuracy of radiocarbon dating performed on bulk sediment, which can have given either too old or too young sediment age.
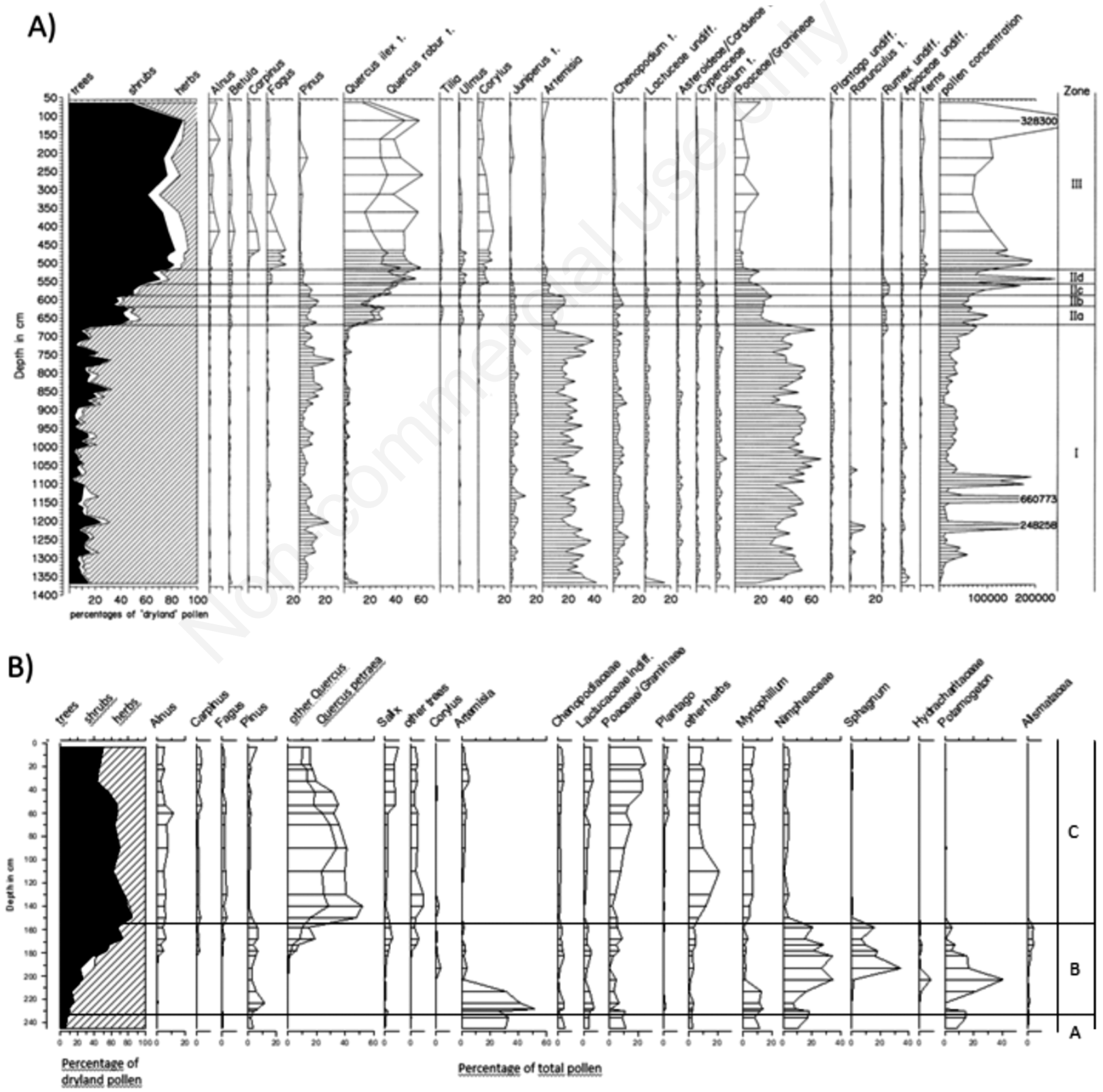

Fig. 2. Pollen profile from Lake Albano core 1E (A, Lowe et al., 1999) and Lake Monterosi core 1A (B, redrawn from data in Bonatti, 1970). 


\section{Alternative interpretation}

Comparing the pollen diagrams obtained from other cores taken in the Adriatic Sea (Lowe et al., 1996) and in other lakes in Central (Lowe et al., 1996) and Southern Italy (Watts et al., 1996) with the Monterosi pollen profile (Fig. 2), the similarity is very evident (see an example in Fig. 2).

Making abstraction of the ${ }^{14} \mathrm{C}$ dates reported by Bonatti (1970), an alternative approximated chronology can be obtained by comparing the history of the vegetation development in Central Italy as described by these pollen profiles.

The lower part of the Monterosi pollen sequence, dominated by Artemisia and other herbs, with a low percentage of Pinus, compare well with zone I in the Lake Albano sequence (Lowe et al., 1996) and zone 4 in the Monticchio sequence (Watts et al., 1996), representing the last cold stage. The increase in Quercus and Alnus pollen percentage indicates then the onset of the Holocene. The relatively low resolution of the Monterosi record does not allow the identification of a distinct cold phase during the Younger Dryas episode.

Between 60 and 40-cm depth, the Monterosi pollen profile shows a decrease in tree pollen percentage, together with an increased presence of large $(>40 \mu \mathrm{m})$ pollen grains of Graminaae and of Plantago pollen, which can be interpreted as a sign of relevant human disturbance, in the form of deforestation and the onset of agriculture, comparable with zone $3 \mathrm{c}$ in the Lake Nemi sequence (core PNEMI-1B, Lowe et al., 1996). In the PNEMI-1B core, this zone is located below a tephra layer dated 4.1 kyears BP.

Based on these considerations, it is possible to hypothesize that the sedimentation rate in Monterosi would have been relatively stable, and the dramatic changes in lake ecosystems would not have been correlated with the building of the Roman road, but they would be related to the deglaciation period.

In Lake Albano, the first part of the Holocene was characterized by an increase in lake trophic status, indicated by an increase in both the concentration of algal pigments and the percent abundance of diatoms preferring nutrient-rich waters, such as small Stephanodiscus spp., most probably related to the development of forest soil in its catchment (Ryves et al., 1996). Later on, the percent abundance of small Stephanodiscus decreased, but the diatom assemblage never went back to the previous composition, indicating that the trophic status of Lake Albano decreased, but did not reached the same situation as in the Late Glacial (Ryves et al., 1996).

The development of forests in Lake Monterosi area is indicated by the strong increase in Alnus and Quercus pollen percentage (Fig. 2). In analogy to the trophic evolution of Lake Albano, soil development in the catchment may have triggered an increase in nutrient input in Lake Monterosi, leading to development of planktonic diatoms and cyanobacteria, that replaced the periphytic and epipsammic species. Unlike Lake Albano, in Lake Monterosi there was no sign of a later reduction of trophic status.

This change in the lake ecosystem is coherent with the alternative equilibria described by Scheffer et al. (1993): the nutrient input may have caused a shift from a "transparent" stable status, were the primary production was dominated by aquatic macrophytes and the diatom assemblage was rich in periphytic diatoms, to a "turbid" stable status, dominated by diatom species typical of nutrient rich lakes, and rich in cyanobacteria, chironomid and cladocera, as described by Hutchinson (1970).

After more than fifty years from the original study, it is not possible to verify the correctness of each of the alternative hypotheses on the causes of the dramatic change in Lake Monterosi ecosystem, either deforestation and development of agriculture during the bronze age, or the cutting of the via Cassia. However, the accurate reporting of the data enables this speculation.

\section{CONCLUSIONS}

The multidisciplinary study carried out on the sediment of Lake Monterosi in the 1960s was an important pioneering study that stimulated and oriented palaeolimnological activities in the following decades. Its main result, describing a cold and dry Late Glacial in the northern Mediterranean was confirmed by later studies.

Some aspect of the history of the lakes during the Holocene can be evaluated again, half a century later, on the basis of later information on the limits of the used technique (such as recognizing possible bias in radiocarbon dating of bulk sediment) and later development in ecological theory (such as the definition of alternative stable states in shallow lakes). This exercise is made possible by the accurate and complete reporting of the raw data in a comprehensive report (Hutchinson 1970).

The continuous increase in the availability of new palaeolimnological data makes also possible to compare the behaviour of different lakes, and to find common patterns in order to obtain robust interpretation of the sediment record. Outstanding examples of large scale comparison of common signals in lake sediment are represented for example by the identification of climatic change as the main driver of the recent success of small planktonic diatoms (Rühland et al., 2015) and the synergic effect of increased atmospheric temperature and nutrients input from land promoting the expansion of cyanobacteria in lakes (Turanu et al., 2015).

The present exercise of re-examination of old published data stresses the importance of open data in environmental science (Wilkinson et al.,, 2016). Beside the extensive reporting of raw data in reports and journal supplementary material, global databases such as Neotoma 
(Goring et al., 2018) are an important tool to make palaeolimnological data available to the whole scientific community and their extensive use to store research results cannot be overstated.

\section{ACKNOWLEDGMENTS}

I warmly acknowledge Enrico Bonatti and an anonymous reviewer for their comments and suggestions that greatly improved the quality of this manuscript.

\section{REFERENCES}

Björck S, Wohlfarth B, 2001. ${ }^{14} \mathrm{C}$ chronostratigraphic techniques in pealeolimnology, p. 205-245. In: W.M. Last and J.P. Smol (eds.), Tracking envionmental changes using lake sediments. Basin analysis, coring and chronological techniques. Kluwer.

Bonatti E, 1966. North Mediterranean climate during the last Würm glaciation. Nature 209:984-985.

Bonatti E, 1970. Pollen sequence in sediments, p. 26-31. In: G.E. Hutchinson (ed.), Ianula: an account of the history and development of the Lago di Monterosi, Latium, Italy. Philadelphia, American Philosophical Society.

Chondrogianni C, Aritzegui D, Niessen F, Ohlendorf C, Lister GS, 1999. Late Pleistocene and Holocene sedimentation in Lake Albano and Lake Nemi (central Italy). Mem. Ist. ital. Idrobiol. 55: 23-38.

Franklin JF, 1988. Importance and justification of long-term studies in ecology, p. 3-19. In: G.E. Likens (ed.), Long-term studies in ecology: Approaches and alternatives. Cham, Springer.

Goring S, Graham R, Loeffler S, Myrbo A, Oliver J, Ormond C, Williams J, 2018. The Neotoma paleoecology database: A research outreach nexus. Cambridge, Cambridge University Press: 75 pp.

Hutchinson GE, 1970. Ianula: an account of the history and development of the Lago di Monterosi, Latium, Italy. Philadelphia, American Philosophical Society: 178 pp.

Lowe J, Accorsi CA, Mazzanti M, Bishop A, Forlani L, van der Kaars S, Mercuri AM, Rivalenti C, Torri P, Watson C, 1996. Pollen stratigraphy of sediment sequences from crater lakes (Lago Albano and Lago di Nemi) and the Central Adriatic spanning the interval from Oxygen isotope Stage 2 to the present day. Mem. Ist. ital. Idrobiol. 55:71-98.

Moss B, 1998. Ecology of fresh waters. Man and medium. Past to future. 3rd ed. Oxford, Blackwell Publ.: $557 \mathrm{pp}$.

Oldfield F, 2005 Environmental change - key issues and alternative approaches. Cambridge, Cambridge University Press: $386 \mathrm{pp}$.

Ruggiu D, Morabito G, Panzani P, Pugnetti A, 1998. Trends and relations among basic phytoplankton characteristics in the course of the long-term oligotrophication of Lake Maggiore (Italy). Hydrobiologia 370:243-257.

Rühland KM, Paterson AM, Smol JP, 2015. Lake diatom responses to warming: reviewing the evidence. J. Paleolimnol. 54:1-35.

Ryves DB, Jones VJ, Guilizzoni P, Lami A, Marchetto A, Battarbee RW, Bettinetti R, Devoy EC, 1996. Late Pleistocene and Holocene environmental changes at Lake Albano and Lake Nemi (Central Italy) as indicated by algal remains. Mem. Ist. ital. Idrobiol. 55:119-148.

Scheffer M, Hosper SH, Meijer ML, Moss B, Jeppesen E, 1993. Alternative equilibria in shallow lakes. Trends Ecol. Evol. 8:275-279.

Smol JP, 2009. Paleolimnology, p. 462-471. In: In: G.E. Likens (ed.), Encyclopedia of inland waters. Academic Press.

Taranu ZE, Gregory-Eaves I, Leavitt PR, Bunting L, Buchaca T, Catalan J, Domaizon I, Guilizzoni P, Lami A, McGowan S, Moorhouse H, Morabito G, Pick FR, Stevenson MA, Thompson PL, Vinebrooke RD, 2015. Acceleration of cyanobacterial dominance in north temperate-subarctic lakes during the Anthropocene. Ecol. Lett. 18:375-384.

Watts WA, Allen JRM, Huntley B, 1996. Vegetation history and palaeoclimate of the last glacial period at Lago Grande di Monticchio, Southern Italy. Quat. Sci. Rev. 15:133-153.

Wetzel, R 2001. Limnology. Lake and river ecosystems. Amsterdam, Elsevier: 1006 pp.

Wilkinson M, Dumontier M, Aalbersberg IJJ, Appleton G, Axton M, Arie Baak, et al., 2016. The FAIR Guiding Principles for scientific data management and stewardship. Sci Data 3:160018.

Zolitschka B, Negendank JFW, 1996. Sedimentology, dating and palaeoclimatic interpretation of A 76.3 ka record from Lago Grande di Monticchio, southern Italy. Quatern. Sci. Rev. 15:101-112. 